\title{
Reappraising Learning Technologies from the Viewpoint of the Learning of Mathematics
}

\author{
Lenni Haapasalo and Peter Samuels
}

\begin{abstract}
Within the context of secondary and tertiary mathematics education, most so-called learning technologies, such as virtual learning environments, bear little relation to the kinds of technologies contemporary learners use in their free time. Thus they appear alien to them and unlikely to stimulate them toward informal learning. By considering learning technologies from the perspective of the learner, through the analysis of case studies and a literature review, this article asserts that the expectation of these media might have been over-romanticised. This leads to the recommendation of five attributes for mathematical learning technologies to be more relevant to contemporary learners' needs: promoting heuristic activities derived from human history; facilitating the shift from instrumentation to instrumentalisation; facilitating learners' construction of conceptual knowledge that promotes procedural knowledge; providing appropriate scaffolding and assessment; and reappraising the curriculum.
\end{abstract}

Key words and phrases: conceptual knowledge, informal learning, instrumental genesis, learning technology, procedural knowledge.

ZDM Subject Classification: C10, C30, D30, E10, R20, Q30, U70.

\section{Introduction}

\subsection{Aim, assumptions and structure}

The term 'learning' traditionally means the content which a student acquires from a curriculum either inside the classroom or in their personal study time. As we wish to emphasize the power of immersive and interactive environments that the utilization of technology can create, our first assumption is not to place 
these restrictions on the term 'learning' but also to consider learning outside the curriculum and in non-study times. Secondly, we stress the need to solve the conflict between conceptual and procedural knowledge: does the learner have to understand before being able to perform a task, or vice versa? ([1]) These aims are consistent with the seven challenges, proposed by [1] for instrumental orchestration within technology-based learning environments: (1) Promoting collaborative social constructions; (2) Linking of conceptual and procedural knowledge; (3) Solving the dilemma between a systematic approach and minimalist instruction; (4) Relating instructional design and assessment to instrumental genesis; (5) Promoting learning by design; (6) Revitalizing sustainable heuristics in human history; and (7) Applying business principles to overcome the bad reputation of mathematics.

Adopting the approach previously suggested in [2], we identify five recommendations implied by these challenges. We provide and evaluate evidence supporting them from associated studies, and shortly discuss the changing role of teachers and the curriculum. We would like to make the reader aware that instead of concentrating on just one or two single issues at a time, the title requires discussion of several perspectives simultaneously. The authors are sorry that the restriction of the length of the article allows open up just the most crucial concepts in the following three sections. There are numerous well-known concepts (e.g. non-formal and informal learning), the characterization of which can be easily found on the Internet.

\subsection{Mathematics interpreted through sustainable heuristic activities}

When considering the learning of mathematics within constructivist paradigm, instead of speaking about 'learning environments', it might be more relevant to adopt the term investigation space (see [2], p. 1489) and [3]), whereby the learning is considered rather as an investigation process - whether individual or collaborative - including both cognitive and psychological aspects. The term 'space' indicates that this process is independent of time, place and formal modes and emphasizes students' own freedom and control. To consider how mathematical knowledge and mathematical thinking enters human mind and life, it is appropriate to recognize which heuristic activities have been sustainable in history.

During his long-term study of the history of mathematics, Zimmermann ([4], [5]) identified eight main activities which have led very often to mathematical innovations over different times and cultures for more than 5000 years. We will 
henceforth refer to these as the Z-activities, represented in Figure 1. He was inspired to create Figure 1 by an old picture from a book by Leibnitz, who in turn had taken it from a 16th Century drawing by Clavius, representing parts from the philosophy of Aristotle. The development of the Octagon must be seen as an extension of Zimmermann's research on mathematical beliefs and on the history of problem solving during several decades. This has been carried out using theoretical analyses of heuristic problem solving and the philosophy of science and cognition. The meta-study $([6])$ gives a comprehensive evaluation of the Z-activities based on well-established criteria for the quality of research in mathematics education (e.g. [7], [8], and [9]). They emphasize the significance, rigor, and both theoretical and pragmatic relevance of the Z-activities, which can be linked to Bishop's ([10]) comprehensive analysis of educational consequences from a sociocultural perspective, as his "concept-based components": counting, locating, measuring, designing, playing, and explaining. On the other hand, measuring, for example, comprises almost all of the Z-activities and their linkage.

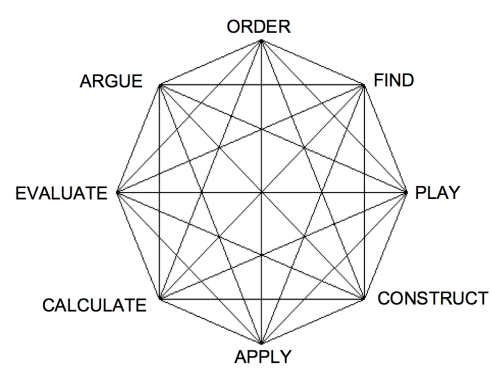

Figure 1. Activities and thinking tools which proved to be successful in mathematics making ([5], p. 42)

Even though numerous other studies have detected general phases in history, general styles of thinking in the history of science, and general laws in history of mathematics (e.g. [11]), there are few studies that focus on such activities that produced new mathematics over a long range of time and on evaluating these activities from a cognitive perspective. When reflecting upon the Z-activities from an educational point of view, it can be recognized in many empirical studies (cf. e.g. [12]) that they are just as important for today's mathematics and science instruction, especially if the creative activities of pupils are stressed. The interconnections between these activities, represented in Figure 1, correspond to the general goal (of learning) to achieve a high degree of flexibility in thinking, 
and to foster connected, divergent thinking $([13])$ in addition to mastering routine activities.

To give a simple example in children's everyday life: You have to evaluate in a few seconds in a pizzeria queue, which of the two drinks would be cheaper per unit: $3 \mathrm{dl}$ for 4 Euro, or $2 \mathrm{dl}$ for 3 Euro? Instead of struggling with applying fractions (which would mean staying at the calculate-corner in the octagon), an ancient strategy linking many other activities is not only viable but faster: Taking the same amount $6 \mathrm{dl}$, we see immediately that the first one is cheaper.

Students use in their everyday life even much more sophisticated methods as false position, successive approximation, for example. In spite of that, the school neglects those strategies, not at least because the traditional Western history of mathematics focuses upon ancient Greece, where the Euclidean and Archimedian tradition emphasized arguing, rules and using a conceptual structure ([14]). However Zimmermann's study concludes that pragmatic aspects (especially the right-hand side of the octagon) have played the most important role. He found this was particularly true in ancient China where there was much less interest in mathematical proof.

\subsection{Instrumental genesis and instrumental orchestration}

When emphasizing that mathematics should be taught both theoretically ('on paper') and in practice (such as 'actual surveying in the field'), the well-known Dutch mathematician Stevin ([15]) suggested that tools such as rulers, compasses and right angles should be replaced by "fieldwork tools". So, it is appropriate to ask what else are the tools for contemporary students than technological ones.

Conflicting opinions over the use of technology in mathematics can be traced back as least as far as the seventeenth century with the invention of the slide rule ([16]). Oughtred ([17]) argued against their use in true mathematics, claiming, "the true way of Art is not by Instruments, but by Demonstration: and that it is a preposterous course of Artists, to make their Schollers only doers of tricks, as it were Juglers" (p. sig. A3 verso), whereas Delamain, his erstwhile student, argued that mechanical aids helped people understand how to calculate $([16])$.

An approach to resolving this conflict from the modern era of computer algebra systems is the theory of instrumental genesis, introduced by [18] and [19], based on a view of technology that distinguishes between artefacts and instruments. According to [20], an artefact is a physical object but an instrument is partly the physical object and partly the cognitive schemes that enable it to be used to perform specific kinds of task; in other words, the artefact becomes an 
instrument, or tool, for these tasks. We shall use the term instrumental genesis in a wide sense to mean the development of information and communication technology (ICT) together with its usage for acquisition of conceptual and procedural knowledge.

Instrumental genesis comprises of two parallel components: instrumentation and instrumentalisation ([18], [19]). The former refers to a person's ability to use a tool. It is directed towards an artefact and describes the process by which it becomes useful to the learner to accomplish specific purposes (that is, an instrument). The latter refers to the way a person uses a tool to shape the actions and the character of the knowledge constructed with the tool. It is directed towards the learner and describes the process by which the possibilities and constraints of the artefact shape his or her conceptual and procedural skills.

Instrumentation and instrumentalisation often naturally happen in students' free time as they tailor their smartphone and tablet apps in creative way for their own purposes. This suggests that mathematical instruction should shift its focus from well-prepared classroom lessons to instrumental orchestration. We use this term, introduced by [18] to mean intentional and quasi-systematic organisation of available ICT tools within an appropriate paradigm of teaching and learning to promote students' instrumental genesis. Our examples will enlighten the three components, defined by [21]: didactical configuration, exploitation, and didactical performance. By using the term "quasi", we emphasize two aspects from the teacher's side: firstly, the need to plan the learning environments systemically, based on viable and sustainable theories of teaching and learning; and secondly, the need to accept the principle of minimalist instruction (see [22]) because the learning very often proceeds more or less spontaneously. The example in Section 2.2 illustrates how the integrated environment of a computer algebra system (CAS) and a dynamic geometry system (DGS) (see [23]) allow casual playing between mathematical representations, offering a powerful tool for problem solving and promotion of links between procedural and conceptual knowledge. Examples of this kind of technology are [24], [25], and [26].

\subsection{Promoting the links between conceptual and procedural knowledge}

The discussion above leads us to ask: Which kind of conceptual and procedural knowledge might be attainable through instrumentalisation? When scaffolding the learning of procedures and operations in mathematics, one of the key questions is how to promote the acquisition of both of these knowledge types whilst avoiding a polarization between recipe-orientated, methods-based teaching 
and an abstract conceptual approach. Instead of giving a cavalcade of researchers' views here, we utilize the following characterizations in [27], based on a comprehensive literature review, and fitting the aims of our paper:

- Procedural knowledge (PK) denotes dynamic and successful use of specific rules, algorithms or procedures within relevant representational forms. This usually requires not only knowledge of the objects being used, but also knowledge of the format and syntax required for the representational system(s) expressing them.

- Conceptual knowledge (CK) denotes knowledge of particular networks and a skilful "drive" along them. The elements of these networks can be concepts, rules (algorithms, procedures, etc.), and even problems (a solved problem may introduce a new concept or rule) given in various representational forms.

Their analysis reveals four views on causal dependencies between PK and CK:

- Genetic view: PK is a necessary but not a sufficient condition for CK.

- Dynamic interaction view: CK is necessary but not sufficient for PK.

- Simultaneous activation view: PK is necessary and sufficient for CK.

- Inactivation view: PK and CK are not related.

Based on these views, they define two pedagogical approaches, the developmental approach and the educational approach. The first one is based on the idea that PK precedes CK, whilst the latter assumes the opposite. They found support for the former from the dominance of procedural knowledge over conceptual knowledge in the development of mathematics, which they attributed to its makers primarily being guided by pragmatic concerns. On the other hand, they use the latter as an attribute of the term 'education'. If we agree with their review that the main goal of education is to develop both PK and CK and to make links between the two, crucial questions are: firstly, what is the quality of technological application?, and secondly, how do different technologies and pedagogical solutions affect the relation between these two knowledge types? We will come to this question later on when giving empirical examples.

\subsection{Contemporary learners and informal learning}

Numerous researchers have expressed their concern of e-learning systems, such as virtual learning environments. For example, social networking sites are rarely used for discussing academic content but more commonly for discussing 
social aspects of learning $([28])$. [29] state that these sites appear for some contemporary learners alien as regards utilizing them for the learning purpose. As remarked by [30], the digital natives ([31]) have become educational immigrants to common types of educational technology. Thus, many educationalists have sought to exploit technologies within education with which digital natives are familiar. Apart from the importance of theory-based design (c.f. [32]), the effective use of these technologies depends upon a sociocultural understanding of their impact within learning. As regards games, the use of incremental learning content makes games user adaptable, leading to psychological "flow" ([33]).

The well-known concepts non-formal and informal learning have been recognized as important ways of learning by numerous researchers and authorities, such as [35]. By studying the relationship between technology and mathematics education from five perspectives, [36] suggests that, "instead of speaking about 'implementing modern technology in the classroom' it might be more appropriate to speak about 'adapting mathematics teaching to the needs of information technology in modern society".

Most contemporary learners own a smartphone and have access to tablets and games consoles. They are generally fluent with content creation and sharing via social networking and both individual and multi-user digital gaming. Such uses of technology for recreation in students' free time inevitably also have an informal learning element. Several authors, such as [31] and [37], have suggested that technology educators should begin by appreciating students' familiarity with such technologies in an informal context as the basis for designing learning technologies in a formal educational context. One expression of this is the serious games movement (e.g. appearing in 10 references in [31]) which seeks to exploit students' gaming familiarity for an educational purpose. An example of mathematical serious games are those available from the Mangahigh website ([34]).

Before going to our remarks, we feel it is appropriate to look back on the evolution of learning technologies.

\subsection{An overview on the paradigms when utilizing learning technology}

The theoretical discussions about the use of computers in education started in the mid-1960s within Skinner's ([38]) programmed learning. This involved delivering information in small segments, allowing self-paced learning, and providing immediate feedback. In the era of computer assisted instruction ([39]) the computer was seen as a presenter of learning material, and monitored student progress. The term computer-based learning ([40]) was later coined as if to pave 
the way for new paradigms of teaching and learning utilizing technology. Early examples are instructional films, (such as [41]), that were used in the USA from $1908([42])$.

The dominant educational approach used with educational technologies until 1980s was instructivist. The widening of the underpinning educational theory on the use of computers in education led to broader terms such as e-learning and technology-based learning ([43]) which generally refer to the learning of content via any digital technology using any educational method. However, this has coincided with a growing tendency to embrace the adoption of new technologies without considering appropriate educational theory behind their effective use ([32]).

From a social perspective, the use of the term learning technology can be traced back at least as far as 1976 ([44]). It is commonly seen as a contemporary variant of the term educational technology which was first used by the US-based Association for Educational Communication and Technology in 1972 and relates to the facilitation and management of a range of learning resources ([45]). [46] defines learning technology as, "the broad range of communication, information and related technologies that can be used to support learning, teaching, and assessment" (c.f. e-learning above).

Constructivism ([47]) and social constructivism ([48]) are widely recognised as viable theories of teaching and learning. Constructivist approaches to learning with computers have been applied within environments such as microworlds ([49]) and simulations ([50]) which allow users to interact and develop conceptual understanding about the effects of different virtual actions. Recently there has been a growing emphasis on the use of mobile digital devices with the advent of mobile learning ([51]). In addition, social interaction has been emphasised in learning along with the creation and sharing of content ([37]) under the Web 2.0 paradigm shift ([52]), such as through blogs and wikis ([53]). These changes have led increasingly to a view of learning being independent of time, place and formal modes of instruction and of education being more learner-centred or learning community-centred.

We are now ready to present our five Recommendations with empirical groundings. Apart from research embedding in the Introduction part, the only empirical examples fitting our viewpoint come from the research group of the first author. 


\section{Recommendations}

\subsection{Promoting sustainable heuristic activities}

To give a grounding, we need examples that show which kind of teaching and learning, whether technology-based or not, supports or does not support the Zactivities. Unfortunately, to our knowledge, the only empirical research that has been carried out with an instrument to measure the Z-activities is that carried out by the research group led by the first author. At the beginning of their so-called ClassPad Project, Eronen and the first author ([54]) emphasized that changing representation with CAS/DGS (c.f. [55]) not only enhances problemsolving processes but also assists with concept formation and understanding. At the beginning of the project, the unfamiliar ClassPad calculator was demonstrated briefly to a class of Year 8 students $(\mathrm{N}=15)$ to give them opportunity to play with it voluntarily during their summer holiday with concepts of Year 9 mathematics (such as a linear function). Their only duty was to write a portfolio of reflective notes if they worked with the tool. All these students accepted this opportunity and played actively with the tool, and three of them also wrote portfolios.

To develop an instrument, each of the Z-activities was quantified by a 1 to 5 distance from the centre of the octagon to denote the strength of the activity (see Figure 2). Thus, a Likert scale instrument was developed to measure:

- Math-profile: The strength of each activity the student thinks is needed when using or learning mathematics.

- Identity-profile: How good the student thinks he or she is in performing each activity.

- Techno-profile: How strongly the student thinks a computer can assist in the performance of each activity.

Figure 2 represents profile shifts of a student who was quite poorly motivated to learn mathematics in classroom but worked voluntarily with ClassPad during her summer holiday. Possible explanations for the profile shifts were explored by interviewing the student who stated, "In May I could not even think to play with the ClassPad in the summer holiday. However, I noticed, that it was very capable for playing with mathematics." Whilst a strong positive shift occurred in her playing techno-profile, surprisingly there was also a negative shift in her calculating profile. This could be explained by a link between this student's increasing awareness of the versatility of the technical tool and a widening of her perception of the utility of a CAS tool than just for supporting calculation. 

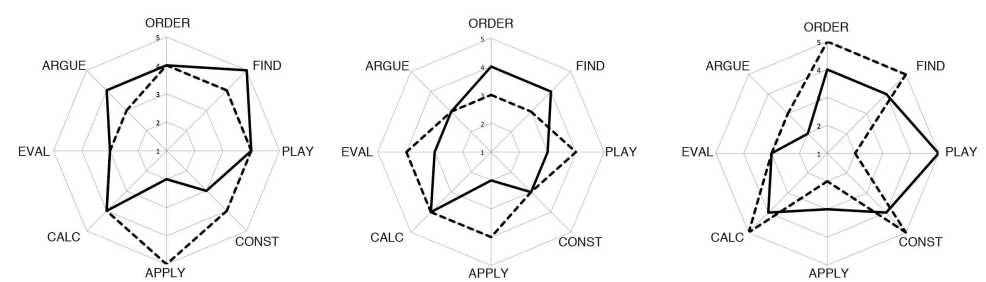

Figure 2. Mean Z-profiles before (dashed) and after (normal) the student's ClassPad work. Math-profile on the left, Identity-profile in the middle, and Techno-profile on the right ([54], p. 714)

Motivated by this surprising outcome, the first author and Eskelinen ([56]) wanted to find out how a group of 116 elementary level teacher trainees at the beginning of their university studies in September 2012 thought they could do each of the Z-activities (i.e. self-confidence) and how strongly they thought each activity was involved during their mathematics lessons in school (i.e. a Mathprofile) and when using ICT, wherever and however it was used (i.e. a Technoprofile). The underlying assumption of the study was when a certain activity is present when a person does, sees or hears something, he or she gets some kind of support for that activity in one way or another. The study found that the support the subjects gained (in the sense of the assumption above) for the Zactivities from their total usage of ICT was even more modest than what they gained from their mathematics lessons in school (see Figure 3).

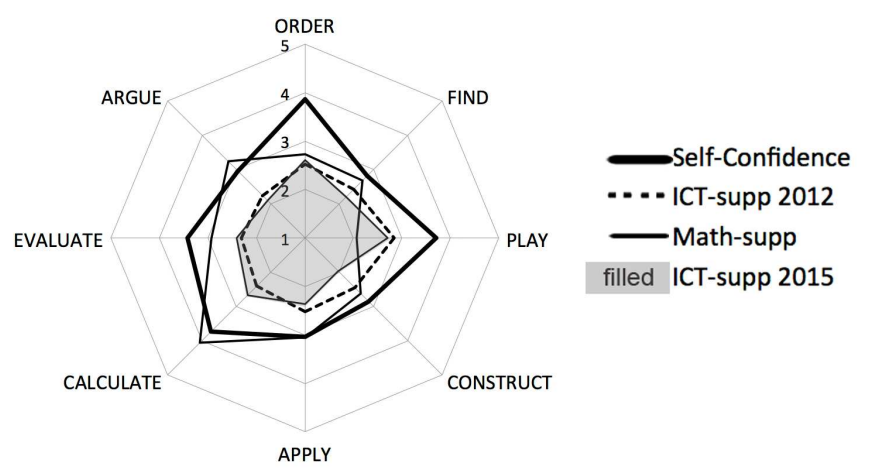

Figure 3. Mean profiles of 116 elementary level trainee teachers in 2012: Identity -profile (thick), Math -profile (thin), and Techno -profile (dashed). The shaded polygon in the middle represents the Techno -profile of a corresponding new group of 114 trainee teachers in 2015 
The outcome was reinforced with an extended instrument whereby each of the Z-activities was divided into three sub-activities (see [56], 2014, p. 92-94). A repeat study in 2015 with a different group of 114 elementary level teacher trainees at the beginning of their university studies indicated a decreasing trend in their view of ICT support (see the shaded polygon in Figure 3). There was evidence of a decrease in find and play $(p<0.05)$, and construct $(p<0.001)$. The latter also held for all sub-activities with $p<0.001$.

When comparing Figures 2 and 3, the findings suggest that ClassPad calculators were viewed among 8th grade students as a MLT in the sense of our paper, whilst ICT was viewed among teacher trainees as only having recreational value. However, collaborative working culture utilizing learning technologies in the spirit of our paper during a course of mathematics didactics caused a positive shift in the teacher trainees' views of ICT support. Figure 4 summarizes their findings that in all Z-activities but playing and finding a significant increase occurred. In the Math-profiles a significant positive shift occurred in ordering, finding, playing, applying, and evaluating, whilst the Identity-profiles remained quite constant. All the above-mentioned shifts were reinforced when using an extended instrument whereby every main activity was divided in three sub-activities (see [56], pp. 92-94).
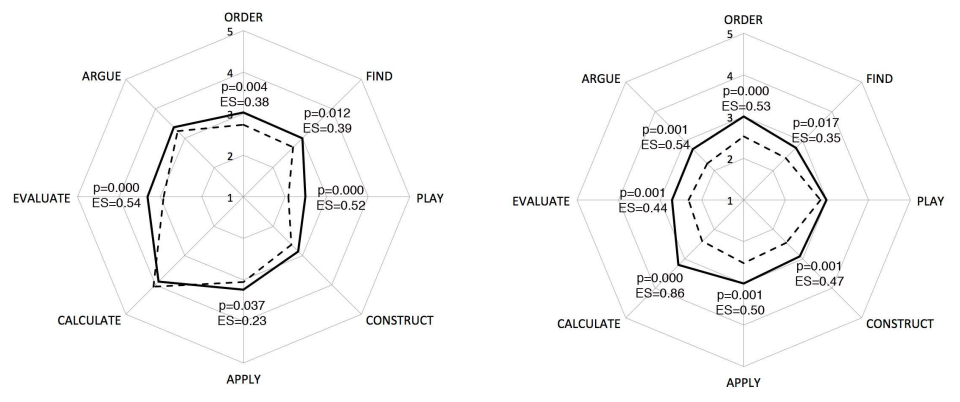

Figure 4. Shifts in elementary level trainee teachers' the Math -profiles (left) and Techno -profiles during a pedagogical course ([56], p. 91)

\subsection{Promoting instrumentalisation}

This title means that Mathematical Learning Technology (MLT) should allow students to modify their built-in knowledge to suit their particular needs. This is justified by analysing verbal accounts of students' thinking processes into 
how those two conceptions are related to each other. The analysis of reflective notes in students' portfolios made this possible. To introduce empirical evidence, we take an extract from the portfolio written by the student mentioned in the previous Section (see [57], p. 88). The sample in Figure 5 illustrates the simultaneous activation principle described below. By manipulating the equation (conceptual interpretation) spontaneously, the student explained how the parameters affect the position and location of the line (procedural interpretation). As instrumentalisation means that the tool shapes the actions and the character of the knowledge constructed with the tool, we notice that the student made her own interpretation against the standard view: the line moves along the horizontal axis. This finding appears surprising, as reported in [36] (p. 3) about students' and teachers' poor metacognitive skills when working with a simple identification task of a well-tailored learning program (downloadable from http://wanda.uef.fi/lenni/programs.html): the subjects changed all problem components at the same time just to get a mismatch and data overflow without noticing essential things.

The equation is now $y=2 x-3$.

I move into the origin the straight line that becomes from the equation. When changing the equation to $y=2 x-5$, the line moves

$$
\begin{aligned}
& a-b \\
& y=2 x-3 \\
& c-d \\
& y=2 x-5 \\
& e-f \\
& y=2 x-1
\end{aligned}
$$

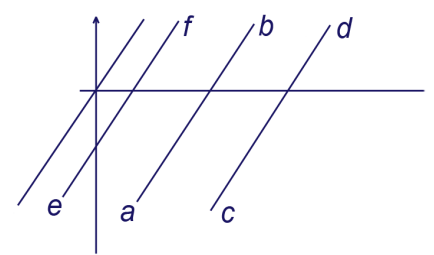

forwards to the positive $x$-axis.

By changing the equation to $y=$ $2 x-1$, the line goes to same direction as before, but the distance is smaller.

Figure 5. Example of instrumentalisation during spontaneous ClassPad work

\subsection{Facilitating learners' construction of conceptual knowledge that} promotes procedural knowledge

The study of Lauritzen ([58]) of 476 economics undergraduate students within a mathematical context reveals two crucial factors in acquiring and applying knowledge. Firstly, PK is necessary but not sufficient for CK; and secondly, to be able to apply what they know, students also need CK. Combining these 
demands, we conclude that developmental approach needs to be combined with educational approach (see Figure 5). The simultaneous activation of CK and PK lies at the intersection of these two approaches. Therefore it might offer the most promising perspective, especially regarding the usage of technology. Very often it means changing the representation.

This Section's title provides a warning against the belief that there is a shortcut to applying knowledge. To establish this assertion we first need a comprehensive analysis how CK and PK are related to each other. Secondly, we need empirical studies where an appropriate instrument to scaffold and measure CK has been used, even within technology-based environments. The long-term MODEM Project of the first author (see [1], [36], or [59]) offers a framework for this, and the dissertation of Lauritzen ([58]) reinforces this assertion with a rigid empirical study.

To pick up the core features of the MODEM framework, we refer to Figure 6. When planning a constructivist approach to the mathematical concepts under consideration, the focus is on the left-hand side when the students try to interpret a tailored problem situation based on more or less spontaneous PK. On the other hand, when offering students opportunities to construct links between representation forms of a specific concept, the focus is on the right-hand box, in which the stages of mathematical concept building are illustrated. In learning situations, however, students must have freedom to choose the problems that they want to learn how to solve, accompanied by continuous self-evaluation instead of relying on the expressed guidance of teachers. The next Section includes an example to solve this dilemma.

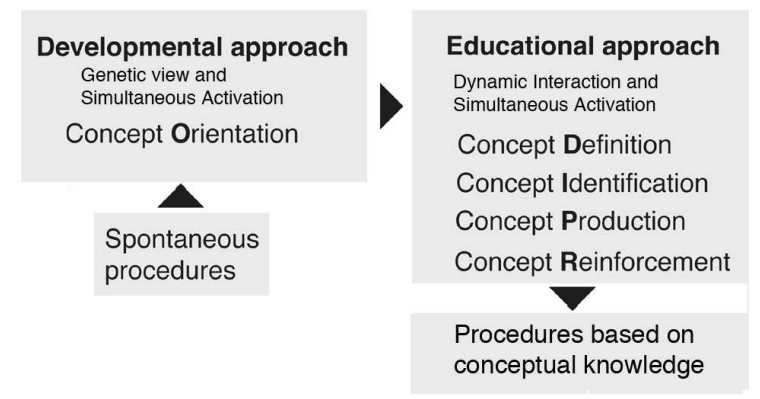

Figure 6. Interplay between the two approaches ([36], p. 3)

Eronen and the first author ([54], p. 707-708) were encouraged by the findings represented in Section 3. They therefore planned and implemented the learning 
(which they referred to as instrumental orchestration) of a whole Year 9 mathematics class merely using the ClassPad calculator without any textbooks and traditional homework. The longitudinal follow up during this stage of the project provided opportunities to analyse students' cognitive and affective development, especially the relationship between their CK and PK when measured in a pre-test, a post-test, and a delayed test.

The learning tasks for linear functions were planned according to the MODEM framework. The students had complete freedom to choose a problem set from the so-called problem buffet, and to decide how they would work during the lessons. Students' choices were recorded in order to find out how a quasisystematic framework could be used within a minimalist approach to instruction.

[54] reports, firstly, that students' scores in almost all test items were significantly higher after the working period than in the pre-test. For most of the test items, these students' scores were higher than those of students even at the end of junior high school, after gaining conventional mathematics teaching (see [1]). Secondly, these students' scores (especially in the production tasks) were even better in the delayed test after three months.

The positive nature of these results somewhat contradicts [60] that minimally guided instruction is less effective and less efficient than other instructional approaches. Eronen ([3]) elaborates on what had actually happened during the learning processes, and what might have contributed to the positive results. His findings suggest that optimal student-centred learning emphasizes students' freedom to choose learning objectives and working methods in problem-based socioconstructivist technology-based environments, in which open questions about both mathematics and technology are solved in collaboration between students or between student teams. Even though students proceeded in a way that leads to unexpected situations (cf. [61]), it was found that learning to link conceptual and procedural knowledge could be organized successfully within this framework.

\subsection{Providing appropriate scaffolding and assessment}

Instrumental genesis changes the essence of mathematics education so radically that instrumental orchestration and assessment should be considered from a new perspective. As [27] and [59] emphasize, instead of as testing, assessment should be interpreted in a global sense as the planning and control of the instrumental orchestration during the whole learning process. It should reflect aspects emphasized in the titles of the former sections. However, even though in many countries the obstacles to using modern technology in both teaching and 
assessment have been removed, at least formally, most tasks used in teaching and examinations are of a quite degenerate type, providing the starting point and concepts, and usually at least the name of the method. The student has to find the end point, namely the correct solution. [57] discusses in detail why this type of task is not only almost opposite to authentic problems occurring in real life but causes a dead end when used for teaching or assessment purposes.

The ClassPad project gave possibilities to analyse new kinds of tasks, including appropriate tutoring. Even though Sections 2 and 3 might give the impression that students could automatically use technology in a sophisticated way during their free time, it is important to emphasize the role of the investigation problems that the teacher (Dr Eronen) gave the students. Thus, an appropriate tutoring was intrinsic, at least as regards the psychological meaning of the problems. The fact that the teacher had gained educational psychological information on his students over several years was crucial regarding the problem posing. As soon as the work was extended to 9th grade in the classroom, several pedagogical variables were involved. Therefore the instrumental orchestration was carefully planned to combine quasi-systematic and minimalist approaches, as reported in detail in [3].

The examples in Section 2 show what usually happens if an appropriate instrumental orchestration is missing: students appear to use technology for social purposes, i.e. as a source of entertainment. This causes concern regarding the populist terms "flipped classroom" and "flipped learning" ([62]). The question of whether to flip schoolwork to homework or homework to schoolwork is somewhat irrelevant in the spirit of our paper. The flipped classroom philosophy of [62] shifts instruction to a learner-centred model in which class time is dedicated to exploring topics in greater depth and creating meaningful learning opportunities, while educational technology, such as online videos, are employed to deliver content outside of the classroom. This idea is not new and can be viewed as a reinvention of the Computer Assisted Programmed System of Instruction ([63]). However, to our knowledge, there are no empirical studies where the planned learning environments align with the spirit of our paper. Instead, there are numerous examples showing that missing appropriate tutoring means missing appropriate behaviour in problem solving situations (e.g. [64]).

In terms of the use of technology in mathematics education, [65] use a metaphor from motorcar racing to assert that school should be seen as a pit stop for learning experiences rather than the place of the race itself. This requires a fundamental reconceptualization of education and the place in which it occurs, with an emphasis placed on students' self-motivated informal learning. Support for 
this view can be found from [66] which provides strong evidence that the ability to solve creative mathematical problems is associated with general creative thinking and attendance of free time activities in mathematics. Also, [13] challenges the modern educational paradigm which he claims promotes convergent thinking, through its emphasis on reductive reasoning, organising students into separate standardized subject classes by age, and individual standardised testing.

When testing the idea of the pit stop philosophy, the first author defined the term in his web-based survey as follows:

"Imagine a car race. You might know that the pit stop is to serve the driver by giving gasoline, new tyres and making necessary adjustments to the car. Let us think that the school would be transformed to a pit stop where the teacher would make, at first together with the students, a plan how a new topic would be processed (cf. what a new racetrack requires), then would represent typical problems of the topic, and would help students to understand the most important concepts and methods of the topic. The students would investigate those problems outside the school by sharing their ideas and questions among themselves and with the teacher by using the Internet and social media. The problems would be tailored to fit the utilization of smart phones, tablets, computers, etc. Instead of normal teaching, the lessons is school would serve mainly as pit stops to give support for processing the problems."

The study among Year 9 students revealed that students think working within the pit stop philosophy would offer support for many of the Z-activities, even more than using ClassPad as the basic tool within normal teaching (see Figure 7).
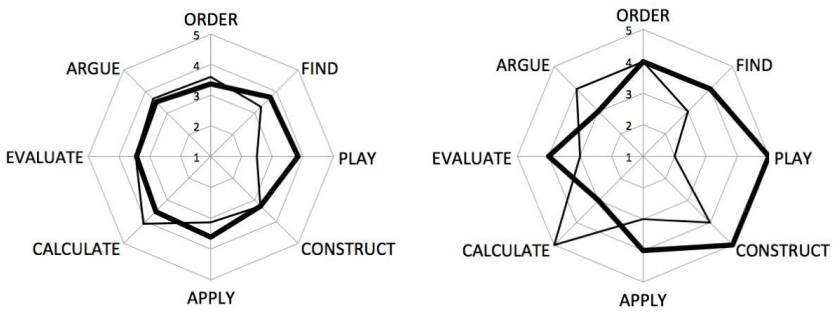

Figure 7. ICT -support that students think they gain from ClassPad work within current school teaching (normal line) and within the pit stop philosophy (bold line). Mean score on the left and mode on the right $([67]$, p. 39) 


\subsection{Reappraising the relation between technology and curriculum}

Numerous prominent researchers have emphasized the importance of informal mathematics and problem solving instead of merely collecting a set of basic skills and concepts to be learned before any engagement can be attempted with the actual practice of mathematics. Freudenthal ([68]), for example, argues that mathematics should be seen as a mental art and should emphasize active problem formulation and problem solving. Besides presenting the logical organization of mathematical knowledge, the focus should be on developing the students' ability to construct and understand knowledge instead of merely collecting data. Studies (e.g. [69]) show that, besides not only being poor problem solvers, teachers often also have strange belief systems about mathematics that they offer to their students, politicians, and parents. This is in accord with the criticism of [70] and fits Felix Klein's ([71]) well-known 'double discontinuity'. The case studies introduced above, made by the first author and Eronen, agree with the increasingly held view among researchers that less formal mathematics should be taught.

Even though in many countries technological development in education has been highlighted and supported in many ways, it has been neglected in curriculum design throughout the whole administration ([72]). Furthermore, teaching organisations and the educational administration keep on doing exactly what [73] warns against: placing excessive emphasis on what should be included in the curriculum for different school grades. In conventional formal learning the goals and control usually come from the teacher or textbook, regulated as more or less exact routes. A totally contrasting approach is the open social construction of knowledge, where a student or a student team sets the goals and objectives to reach them. This collaborative innate learning happens very often in the most natural way when a person does not have any extrinsic motivation to learn.

[37] promotes an educational approach to using technology that involves collaboration, creating projects, and donating meaningful results to others. Whilst collaboration appears outside school as natural phenomena, in school it is often called 'cheating' ([13]). For example, Internet forums, such as in open software development communities ([74]) often promote and maintain a collaborative socio-constructivist working culture better than classroom-based work. Individuals often set ambitious goals and commit to work to achieve them by donating their results to each other. Knowledge gained through these processes is not sterile without any transfer, but socially generated and viable, having both cognitive and pragmatic relevance. The evaluation of success should be based on how the 
contribution of each individual helps the entire community to cope with a problem situation, without any special external rewards, incentives, or stereotypical criteria.

Common to these characterizations of learning technology is an implicit assumption that technology being used (correctly) by a typical student will enable them to learn, or at least assist them in their learning. This assumption is often itself based on the assumption that the context of learning technologies is the replacement or enhancement of a traditional educational setting in which learning normally occurs. However, little attention has been paid to whether the learning technology in itself is something with which a contemporary learner might choose to engage if they were not enrolled on a course (assessed and accredited) for which its use was either recommended or compulsory.

Most interpretations of Papert's ([49]) ideas have been through virtual systems (such as turtle graphics) rather than physical robots. [2] argues that combining an integrated mathematical construction and visualisation environment such as GeoGebra with a physical robot encourages mathematical development. They explain how such spontaneous research environments promote Learning by Design, all the Z-activities, social and collaborative construction processes, links between conceptual and procedural knowledge, interaction between systematic design and minimal interaction, adapting assessment to instrumentalisation within society, and serve as inhibitor to students' negative mathematical belief systems.

As regards assessment in the sense of testing, in many countries there is an emerging trend to shift from paper and pencil assessment to electronic assessment. [75] describes the recent development of a mathematical assessment authoring system that is compatible with modern virtual learning environments. However, these developments are very far from a well-organized curriculum where the main purpose is not to increase skill but to promote appropriate links between conceptual and procedural knowledge and promote the Z-activities. A curriculum within a constructivist spirit would regard students as knowledge constructors rather than knowledge users or content consumers (c.f. [76]). This would mean shifting from Web 1.0 paradigm ([77]) to Web 2.0 paradigm ([52]), based on social interaction with the creation and sharing of content. 


\section{Discussion}

To shift the instrumental orchestration in a learning context from a formal instruction to an informal one such as blended learning, flipped learning, or the pit stop philosophy advocated here, educators should be aware that instrumentalisation is a very natural thing in students' everyday lives. In agreement with [78], those informal environments should help learners develop social, cognitive, and metacognitive dispositions that can be applied to learning.

The fact that institutions prefer to remain on the level of instrumentation by trying to perform trivial routines in their computer classes, when at the same time students utilize their instrumentalisation rather for entertainment, triggers a big educational challenge. Our empirical examples illustrate the expertise required by teachers. It is our belief that appropriate scaffolding must be based on empirically tested sustainable but pragmatic pedagogical theories, such as MODEM, for example.

In Recommendation 5 we warned against the view of assessment as testing rather than interpreting. We view assessment as a dynamic process at every stage of scaffolding, whether technology-based or not. Since the 1990's, the importance of assessment in improving mathematics education has been recognised by the International Commission on Mathematical Instruction ([79]). However, international comparisons like TIMSS ([80]) and PISA ([81]) have contaminated serious efforts to respond this challenge by focusing on skill acquisition and standardised problems. Whilst the evidence presented to justify our assertion of five recommendations for MLT has largely been based on the use of CAS-technology we assert that it is generalizable to the use of integrated CAS/DGS and other technology-based environments. We believe they have potential for application to other subject domains sharing common features with the mathematical domain, such as science in general. However, to consider instrumental genesis, for example, from a wider perspective, it would be appropriate to consider whether the same kind of sociocultural approach could be applied in other fields.

We hope that this paper stimulates a serious discussion about how technologies, such as tablets and mobile devices with their dramatically increasing numbers of applications, could be used as learning technologies in the reappraisal we have presented. Our attributes combined with the discussion of the Z-activities also encapsulate the main characteristics of navigationism ([82]) which emphasises learners' opportunities to find, identify, manipulate and evaluate knowledge, and to solve problems collaboratively. This agrees with the conclusion of [83] 
that an integration of technology, cooperative activity design and broader educational practices can impact positively on students' learning. On the other hand, our empirical findings support the view of [32] which also warns against "over-romanticism" regarding contemporary technological opportunities.

Educational practitioners might find the pit stop philosophy too progressive, and even devaluating their role as teachers. However, using our metaphor of a car race, we would like to ask which would a teacher prefer for their status: to drive a car on behalf of a driver (i.e. a student); or to participate as a member of a professional team, offering the best possible car adjustments and test track for a driver (student)? An appropriate test track means the professional orchestration of investigation spaces, whereby requirements for the psychological meaning of problems and sustainable assessment methods are provided.

By using this metaphor we would like to stress that even modest hands-on technologies can be used to promote conceptual and procedural mathematical knowledge provided that the scaffolding fulfils viable research-validated pedagogical theories. However, the design of an investigation space for such a purpose is often much more demanding than planning and managing the development of a new product. As the components relate, create and donate of the Engagement Theory of [37] are suitable for this kind of purpose, we suggest that the create component could be integrated with the Z-activities in a mathematical context. When using constructivist views of mathematics teaching and learning (namely, that concepts and procedures should at least be partially constructed by students themselves) well-known concepts can be applied in one form or the other. Then, the Z-activities show their theoretical and pragmatic relevance because they carry a 5000 year heritage of interpreting how mathematical knowledge and mathematical thinking came into human minds, life and action. The book [55] offers examples of built-in scaffolding for the 'Learning by design' within the pit stop philosophy. Our requirement that the design of investigation spaces should be undertaken from the learners' perspective is also consistent with Jonassen's ([84]) view that those who learn most from the instructional materials are their developers, not their users. 


\section{References}

[1] L. Haapasalo, The conflict between conceptual and procedural knowledge: should we need to understand in order to be able to do, or vice versa?, in: Towards Meaningful Mathematics and Science Education, Bulletins of the Faculty of Education 86, (L. Haapasalo and K. Sormunen, eds.), University of Joensuu, Joensuu, 2003, 1-20.

[2] L. Haapasalo and P. C. Samuels, Responding to the challenges of instrumental orchestration through physical and virtual robotics, Computers \& Education 57, no. 2 (2011), 1484-1492.

[3] L. Eronen, Quasi-Systematic Minimalism within Socio-Constructivist Learning of Mathematics (Unpublished doctoral dissertation), University of Eastern Finland, Joensuu, Finland, 2014.

[4] B. Zimmermann, Heuristik als ein Element mathematischer Denk - und Lernprozesse. Fallstudien zur Stellung mathematischer Heuristik im Bild von Mathematik bei Lehrern und Schülern sowie in der Geschichte der Mathematik, Habilitationsschrift (in German), Universität Hamburg, 1991.

[5] B. Zimmermann, On the genesis of mathematics and mathematical thinking - a network of motives and activities drawn from the history of mathematics, in: Towards Meaningful Mathematics and Science Education, Bulletins of the Faculty of Education 86, (L. Haapasalo and K. Sormunen, eds.), University of Joensuu, Joensuu, 2003, 29-47.

[6] L. Haapasalo and J. Hvorecky, Evaluating the Zimmermann octagon within research standards, in: Konstruktionsprozesse und Mathematikunterricht, Bulletins of the Faculty of Education 86, (T. Fritzlar, L. Haapasalo, F. Heinrich and H. Rehlich, eds.), Franzbecker, Hildesheim, 2011, 145-152,

http://www.promath.de/docs/Konstruktionsprozesse.pdf.

[7] J. Kilpatrick, Beyond face value: Assessing research in mathematics education, in: Criteria for Scientific Quality and Relevance in the Didactics of Mathematics, (G. Nissen and M. Blomhøj, eds.), Danish Research Council for the Humanities, Roskilde, 1993, 15-34.

[8] A. Sierpinska, Criteria for scientific quality and relevance in the didactics of mathematics, in: Criteria for Scientific Quality and Relevance in the Didactics of Mathematics, (G. Nissen and M. Blomhøj, eds.), Danish Research Council for the $\mathrm{Hu}-$ manities, Roskilde, 1993, 35-74.

[9] M. Simon, Raising issues of quality in mathematics education research, Journal for Research in Mathematics Education 35, no. 3, doi: 10.2307/30034910 (2004), $157-163$.

[10] A. Bishop, Mathematical Enculturation: A cultural perspective on mathematics education, Kluwer, Dordrect, 1997.

[11] R. L. Wilder, Mathematics as a Cultural System, Pergamon Press, Oxford, 1981.

[12] M. Lorenzo, The development, implementation, and evaluation of a problem solving heuristic, International Journal of Science and Mathematics Education 3, no. 1, doi: 10.1007/s10763-004-8359-7 (2005), 33-58. 
[13] K. Robinson, RSA Animate - Changing Education Paradigms, 2010, http://www . youtube . com/watch?v=zDZFcDGpL4U.

[14] J.-C. Martzloff, A History of Chinese Mathematics, Springer, New York, 1997.

[15] S. Stevin, De Thiende, Leerende door onghehoorde lichticheyt allen rekeningen onder den menschen noodich vallende afveerdighen door heele ghetalen sonder ghebrokenen, (in Dutch), Christoffel Plantijn, Leiden, 1585, http://anet.uantwerpen.be/digital/opacehc/ehc/dg:ehc:357/N.

[16] H. Higton, Does using an instrument make you mathematical? Mathematical practitioners of the $17^{\text {th }}$ century, Endeavour 25, no. 1 (2001), 18-22.

[17] W. Oughtred, The Circles of Proportion and the Horizontall Instrument, Avg. Mathewes, London, 1632.

[18] D. Guin and L. Trouche, Mastering by the teacher of the instrumental genesis in CAS environments: Necessity of instrumental orchestrations, Zentralblatt für Didaktik der Mathematik 34, no. 5, doi: 10.1007/BF02655823 (2002), 204-211.

[19] M. Artigue, Learning mathematics in a CAS environment: The genesis of a reflection about instrumentation and the dialectics between technical and conceptual work, International Journal of Computers for Mathematical Learning 7, no. 3 (2002), $245-274$

[20] P. Vérillon and P. Rabardel, Cognition and artifacts: a contribution to the study of thought in relation to instrumented activity, European Journal of Psychology of Education 10, no. 1, doi: 10.1007/BF03172796 (1995), 77-101.

[21] P. Drijvers, M. Doorman, P. Boon, H. Reed and K. Gravemeijer, The teacher and the tool: instrumental orchestrations in the technology-rich mathematics classroom, Educational Studies in Mathematics 75, no. 2, doi: 10.1007/s10649-010-9254-5 (2010), 213-234.

[22] J. M. Carroll, The Nurnberg Funnel: Designing minimalist instruction for practical computer skill, The MIT Press, Cambridge, MA, 1990, 7-10.

[23] S. Arnold, Dynamic integration of CAS and DGS: what does this mean?, Compass Learning Technologies, 2009, http://www . compasstech. com.au/ARNOLD/CASandDGS.html.

[24] International GeoGebra Institute, Geogebra, 2017, https://www.geogebra.org.

[25] Casio Computer Co. Ltd., Classpad 330, n.d., https://edu.casio.com/products/cg/cp_v302/.

[26] Texas Instruments, TI-Nspire ${ }^{\text {TM }}$ CX CAS Handheld, 2017, https://education.ti. com/en/products/calculators/graphing-calculators/ti-nspire-cx-cas.

[27] L. Haapasalo and D. Kadijevich, Two types of mathematical knowledge and their relation, Journal für Mathematikdidaktik 21, no. 2 (2000), 139-157.

[28] C. Madge, J. Meek, J. Wellens and T. Hooley, Facebook, social integration and informal learning at university: 'it is more for socialising and talking to friends about work than for actually doing work', Learning, Media, and Technology 34, no. 2, doi: 10.1080/17439880902923606 (2009), 141-155. 
[29] L. Phipps, D. Cormier and M. Stiles, Reflecting on the virtual learning systems extinction or evolution?, Educational Developments 9, no. 2 (2008), 1-4.

[30] P. C. Samuels and L. Haapasalo, Real and virtual robotics in mathematics education at the school-university transition, International Journal of Mathematical Education in Science and Technology 43, no. 3 (2012), 285-301.

[31] M. Prensky, Digital natives, digital immigrants part I, On the Horizon 9, no. 5, doi: 10.1108/10748120110424816 (2001), 3-6.

[32] A. Kirkwood and L. Price, Learners and learning in the twenty-first century: What do we know about students' attitudes towards and experiences of information and communication technologies that will help us design courses?, Studies in Higher Education 30, no. 3, doi: 10.1080/03075070500095689 (2005), 257-274.

[33] M. Csikszentmihalyi, Flow: The psychology of optimal experience, HarperCollins, New York, 1990.

[34] Blue Duck Education, Mangahigh: Bring your classroom to life, 2017, https://www .mangahigh.com/en-gb/.

[35] Organisation for Economic Co-operation and Development, Recognition of non-formal and informal learning - home, 2016, http://www.oecd.org/edu/skills-beyondschool/recognitionofnon-formalandinformallearning-home.htm.

[36] L. Haapasalo, Adapting mathematics education to the needs of ICT, The Electronic Journal of Mathematics and Technology 1, no. 1 (2007), 1-10.

[37] G. Kearsley and B. Shneiderman, Engagement theory: A framework for technology-based teaching and learning, Educational Technology 38, no. 5 (1998), 20-23.

[38] B. F Skinner, The science of learning and the art of teaching, Harvard Educational Review XXIV, no. 2 (1954), 86-97.

[39] R. C. Atkinson, Computerized instruction and the learning process, American Psychologist 23, no. 4, doi: 10.1037/h0020791 (1968), 225-239.

[40] C. A Hawkins, The performance and the promise of evaluation in computer based learning, Computers \& Education 3, no. 4, doi: 10.1016/0360-1315(79)90004-6 (1979), 273-280.

[41] Jam Handy Organization, Around the Corner, 1937, https://archive.org/details/Aroundth1937.

[42] R. A. Reiser, A history of instructional design and technology: Part I: A history of instructional media, Educational Technology Research and Development 49, no. 1, doi: 10.1007/BF02504506 (2001), 53-64.

[43] V. Koller, S. Harvey and M. Magnotta, Technology-Based Learning Strategies, Social Policy Research Associates, Washington, DC, 2008.

[44] J. H. Douglas, Learning technology comes of age, Science News 110, no. 11 (1976), 170-170, 174.

[45] A. Januszewsky, Educational Technology: The development of a concept, Libraries Unlimited, Englewood, CO, 2001.

[46] Association for Learning Technology, What is Learning Technology?, 2016, http://www.alt.ac.uk/about-alt/what-learning-technology. 
[47] Radical Constructivism in Mathematics Education, (E. von Glasersfeld, ed.), Kluwer, Dordrecht, 1991.

[48] P. Ernest, Social Constructivism as a Philosophy of Mathematics, State University of New York Press, Albany, 1998.

[49] S. Papert, Mindstorms: Children, computers and powerful ideas, Basic Books, New York, 1980.

[50] T. T. de Jong, Learning and instruction with computer simulations, Education and Computing 6, no. 3, doi: 10.1016/0167-9287(91)80002-F (1991), 217-229.

[51] Mobile learning: A handbook for educators and trainers, (A. Kukulska-Hulme and J. Traxler, eds.), Routledge, Abingdon, 2005.

[52] T. O'Reilly, What is Web 2.0? Design patterns and business models for the next generation of software, O'Reilly Network, 2005, http://www.oreillynet.com/pub/a/ oreilly/tim/news/2005/09/30/what-is-web-20.html.

[53] J. Hsu, Innovative technologies for education and learning: Education and knowledge-oriented applications of blogs, wikis, podcasts, and more, International Journal of Information and Communication Technology Education 3, no. 3, doi: 10.4018/jicte.2007070107 (2007), 70-89.

[54] L. Eronen and L. Haapasalo, Making mathematics through progressive technology, in: The First Sourcebook on Nordic Research in Mathematics Education, (B. Sriraman, C. Bergsten, S. Goodchild, G. Palsdottir, B. Dahl and L. Haapasalo, eds.), Information Age Publishing, Charlotte, NC, 2010, 701-710.

[55] L. Haapasalo and O. Karkkulainen, CASual Learning of Mathematical Concepts, MEDUSA, Joensuu, Finland, 2017, http://cs.uef.fi/lenni/cas/eng/index.html.

[56] L. Haapasalo and P. Eskelinen, Shifts in teacher trainees' Views of NCTM standards and sustainable activities, in: Spaces for Learning: Past, present and future, Report, no. 36, (A-S. Röj-Lindberg, L. Burman, B. Kurtén-Finnäs and K. Linnanmäki, eds.), Åbo Akademi University, Faculty of Education, Vaasa (2014), 86-98.

[57] L. Haapasalo, Adapting assessment to instrumental genesis, The International Journal for Technology in Mathematics Education 20, no. 3 (2013), 87-93.

[58] P. Lauritzen, Conceptual and Procedural Knowledge of Mathematical Functions, Vol. 34, Dissertations in Education, Humanities, and Theology, University of Eastern Finland, 2012, http://epublications.uef.fi.

[59] L. Haapasalo, Perspectives on Instrumental Orchestration and Assessment from Challenges to Opportunities, Plenary at the 13th ATCM, Thailand, 2008, http://atcm.mathandtech.org/EP2008/papers_invited/2412008_15968.pdf.

[60] P. Kirschner, S. Sweller and R. Clark, Why minimal guidance during instruction does not work: an analysis of the failure of constructivist, discovery, problem-based, experiential, and inquiry-based teaching, Educational Psychologist 41, no. 2, doi: 10.1207/s15326985ep4102_1 (2006), 75-86.

[61] C. Foster, Exploiting unexpected situations in the mathematics classroom, International Journal of Science and Mathematics Education 13, no. 5, doi: 10.1007/s10763-014-9515-3 (2015), 1065-1088. 
[62] J. Bergmann and A. Sams, Flipped learning: Maximizing face time, Talent Development 68, no. 2 (2014), 28-31.

[63] A. Rae and P. C. Samuels, Web-based personalised system of instruction: an effective approach for diverse cohorts with virtual learning environments?, Computers \& Education 57, no. 4, doi: 10.1016/j.compedu.2011.06.003 (2011), 2423-2431.

[64] M. E. Pesonen, L. Haapasalo and T. Ehmke, Critical look at dynamic sketches when learning mathematics, The Teaching of Mathematics 9, no. 2 (2006), 19-29.

[65] L. Haapasalo and B. Zimmermann, Redefining school as pit stop: It is the free time that counts, Invited paper presented at Sixteenth Asian Technology Conference in Mathematics, Bolu, Turkey, 2011, http://atcm.mathandtech.org/EP2011/invited_papers/3272011_19566.pdf.

[66] N. L. Livne and R. M. Milgram, Academic versus creative abilities in mathematics: two components of the same construct?, Creativity Research Journal 18, no. 2, doi: 10.1207/s15326934crj1802_6 (2006), 199-212.

[67] L. Haapasalo, Tietotekniikan viihdekäytöstä kohti varikkofilosofiaa, Dimensio $\mathbf{7 7}$, no. 3, in Finnish (2013), 36-40.

[68] H. Freudenthal, Revisiting Mathematics Education, Kluwer, Dodrecht, 1991.

[69] A. H. Schoenfeld, Explorations of students' mathematical beliefs and behaviour, Journal for Research in Mathematics Education 20, no. 4, doi: 10.2307/749440 (1989), 338-355.

[70] R. Courant and H. Robbins, What is Mathematics? An elementary approach to ideas and methods, 2nd edition, revised by I. Stewart, Oxford University Press, Oxford, 1996.

[71] F. Klein, Elementary Mathematics from an Advanced Standpoint, Macmillan, New York, 1939.

[72] L. Haapasalo and H. Silfverberg, Technology enriched mathematics education, in: How Finns Learn Mathematics and Science, (E. Pehkonen, M. Ahtee and J. Lavonen, eds.), Sense Publishing, Rotterdam, 2007, 163-180.

[73] G. Howson and B. Wilson, School Mathematics in the 1990s, Cambridge University Press, New York, 1986.

[74] M. Ben-Ari, Situated learning in computer science education, Computer Science Education 14, no. 2 (2004), 85-100.

[75] W. Foster, C. Perfect and A. Youd, A completely client-side approach to e-assessment and e-learning of Mathematics and Statistics, International Journal of e-Assessment 2, no. 2 (2004), 1-12.

[76] P. C. Samuels and K. Maitland, Redefining maths learning technologies: putting the curriculum into the fun, in: 1st HEA Annual Conference on Aiming for Excellence in STEM Learning and Teaching, Higher Education Academy, London, 2012, https://www.researchgate.net/profile/Peter_Samuels/publication/262981025_ Redefining_Maths_Learning_Technologies_Putting_the_Curriculum_into_the_Fun/. 
[77] G. Cormode and B. Krishnamurthy, Key differences between web 1.0 and web 2.0, First Monday 13, no. 6 (2008),

http://www.ojphi.org/ojs/index.php/fm/article/view/2125/1972.

[78] D. Hung, S-S. Lee and K. Y. T Lim, Authenticity in learning for the twenty-first century: Bridging the formal and the informal, Educational Technology Research and Development 60, no. 6, doi:10.1007/s11423-012-9272-3 (2012), 1071-1091.

[79] M. Niss, Investigations into Assessment in Mathematics Education: An ICMI study, Kluwer, Dordrecht, 1993.

[80] Institute of Education Sciences, Trends in International Mathematics and Science Study (TIMSS), n.d., https://nces.ed.gov/timss/.

[81] National Council for Educational Statistics, Program for International Student Assessment (PISA), https://nces.ed.gov/surveys/pisa/.

[82] T. H. Brown, Beyond constructivism: navigationism in the knowledge era, On the Horizon 14, no. 3, doi:10.1108/10748120610690681 (2006), 108-120.

[83] J. Roschelle, K. Rafanan, R. Bhanot, G. Estrella, B. Penuel, M. Nussbaum, and S. Claro, Scaffolding group explanation and feedback with handheld technology: Impact on students' mathematics learning, Educational Technology Research and Development 60, no. 6, doi:10.1007/s11423-009-9142-9 (2010), 1071-1091.

[84] D. H. Jonassen, Computers as Mindtools for Schools, Prentice Hall, Upper Saddle River NJ, 2000.

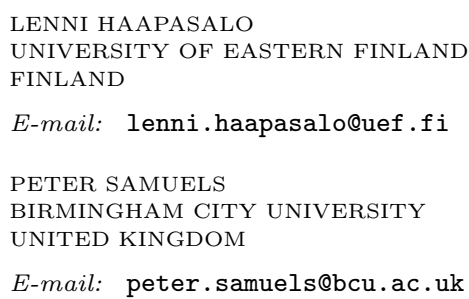

(Received September, 2016) 